\title{
Ignoring our elders: tobacco control's forgotten health equity issue
}

\author{
Tim McAfee $\odot,{ }^{1}$ Ruth E Malone $\odot,{ }^{1}$ Janine Cataldo ${ }^{2}$
}

Over the past decades, demand-side tobacco control efforts in many countries have focused primarily on younger populations, including prevention of initiation in youth and young adults, and encouraging quitting among those in their 20s, $30 \mathrm{~s}$ and 40s. ${ }^{1}$ This focus has been explained primarily based on limited resources and long-term efficiency: it is more cost-effective over many decades to prevent initiation or get someone to quit young than it is to get older people who have smoked a long time to quit. ${ }^{2}$ But there has been almost no examination of this paradigm and its effects from a health equity perspective.

In the US private health insurance sector, smoking status is among few factors besides age that health insurers are legally allowed to use to charge a higher premium amount. $^{3}$ Because premiums for older people are already as much as three times higher than those for younger individuals, the discriminatory effect of this policy is a greater burden for older smokers. Clinicians are also less likely to refer older individuals for cessation support or to prescribe cessation medications. ${ }^{4}$

Public health agencies likewise expend little effort specifically to motivate and help older tobacco users, compared with outreach and specially designed programmes for younger people who are members of priority populations suffering from health disparities. Yet older smokers as a group have grave intersectional disadvantages: they are poorer, less educated, have higher rates of mental illness, are more likely to be non-White, disabled and have multiple chronic conditions than younger smokers. ${ }^{5}$ The lack of attention has consequences: in the USA, smoking prevalence in those 65 and older did not decrease from 2000 to $2015 .^{7}$ This lack of progress is likely due to an actual decrease in quit attempts and successes in older smokers, while among those under

${ }^{1}$ Social and Behavioral Sciences, University of California, San Francisco, California, USA

2Department of Physiological Nursing, School of Nursing, University of California, San Francisco, San Francisco, California, USA

Correspondence to Dr Tim McAfee, Department of Social and Behavioral Sciences, University of California, San Francisco, CA 94143, USA; tim.mcafee@ucsf.edu
45 years prevalence decreased and quit attempts increased. ${ }^{8}$ Although smoking prevalence is lower in those over 65 than in younger groups, this is not due to targeted public health or clinical efforts, ${ }^{9}$ but rather to differential attrition due to markedly increased absolute mortality rates among older tobacco users.

In public health, perhaps the most visible efforts to encourage smokers to quit are large mass media campaigns at the state and national levels. In general, however, older adults have not been a target of these campaigns. Although the rationale for this exclusion is not well documented, the ad development processes for public health antitobacco campaigns have not tested resonance of themes in those over 65 , as has been done frequently for priority/target populations. Elders are rarely featured and are not a media buy focus. This omission is intentional because campaigns prioritise reaching younger smokers. Some focus group evidence suggests that the more negatively framed messages that appeal to youth and middle-aged smokers may not resonate as much with older people, who may respond to positive framing. ${ }^{10}$

In addition, the US Centers for Disease Control and Prevention and most states have not developed community collaborations with or provided funding to senior advocacy groups to work on tobacco, as has been done for eight other identified priority populations. ${ }^{11} 12$ This situation persists even though over two-thirds of the burden of smoking-related morbidity and mortality is concentrated in those over $65,{ }^{13}$ and demographic shifts in the USA suggest that $16 \%$ of the population (63 million people) will be over the age of 70 by $2050 .^{14}$

Notably, the tobacco industry has not adopted a similar hands-off stance. Tobacco industry document research shows that they systematically targeted older adults. Older smokers' fears of the dangers of smoking (and industry's concern that they would quit as a result) led to development of the 'light' and 'low tar' campaigns, falsely conveying to older people the notion that these products were safer. Couponing initiatives and giveaways at nursing homes were targeted to older smokers. $^{15}$
What rationales allow continued discriminatory policies towards older people, despite increased awareness of health equity as a fundamental public health principle? The principal rationale is that by getting young people to not start smoking or quit early, they will eventually avoid all or most smoking-attributable risk. Quitting before age 40 adds around 10 years of life expectancy, while someone aged 55-64 who quits 'only' gains on average 4 years. ${ }^{2}$ Thus, if the cost to prevent initiation in a young adult, or to generate a quit in a 30-year-old, is similar to the cost to generate a quit in a 55 -year-old, then putting limited resources on younger smokers makes a certain economic sense. A pragmatic political consideration has been that the general public and politicians are more inclined to support measures focusing on the young than measures to help older tobacco users to quit.

But what sort of ethical company are we keeping by deprioritising millions of older smokers in the name of efficiency, many of whom will develop diseases and die from the consequences of their continued smoking? This zero-sum game mindset pits the young against the old, focusing on potential benefits to younger people who do not start smoking or quit, even though those benefits will mainly accrue many decades in their future. This efficiency model perhaps reached its zenith (or nadir) in a 2001 study sponsored by Philip Morris and provided to the Czech Republic when it was considering a cigarette excise tax. Examining tobacco's overall economic impact, the study concluded that the early deaths of people who smoked helped the government's finances by decreasing its pension and healthcare obligations. ${ }^{16}$ This argument that maintaining smoking in the elderly is cost-efficient was not generally well-received. Most people did not agree that it was reasonable to let older smokers die in order to preserve either government coffers or tobacco industry profits. But has public health made a similar calculus?

Additional rationales for not systematically addressing smoking among older people include mistaken assumptions that they are not interested in quitting; that they are unlikely to be successful; and that even if they do quit, the damage is already done. However, older smokers are as likely to succeed if they do try to quit, and no more likely to relapse. ${ }^{17}$ Although they may be less likely to make quit attempts, this may not mean they are not interested in quitting, but rather that they are less hopeful regarding success, believe quitting is futile, or have less exposure to 
age-appropriate encouragement and help to quit. ${ }^{18}$ A similar likelihood of success coupled with lower likelihood of trying calls for targeted interventions designed to increase older people's quit attempts, such as mass media campaigns, increased clinical cessation support and communitylevel collaborations.

For older individuals, the urgency of quitting is greater and the harm from continued smoking is more imminent. 'The damage is already done' argument is not supported by the major conclusion of the 2020 US Surgeon General's Report that 'smoking cessation is beneficial at any age', ${ }^{20}$ which has been reinforced by recent prospective studies of hundreds of thousands of older people. ${ }^{21} 22$

More people died from smokingattributable causes in the USA in 2020 alone $(\sim 480000)^{23}$ than from COVID-19 ( 375 000). ${ }^{24}$ What if, during the COVID-19 pandemic, we had applied the same dominant paradigm regarding age that is currently present in tobacco control? Public health would have concentrated on strategies to protect the young and middle aged, viewing those over 65 as essentially a lost cause, of less critical interest because their life expectancy is dramatically shorter. There would have been no fullcourt press to first vaccinate those over 65 , or to develop strategies to treat those with multiple comorbid conditions (predominately seniors). We would have witnessed far more deaths among the elderly, wiping out whole generations.

Seem far fetched? There were vocal minority arguments made as the pandemic progressed that, essentially, the elderly and the infirm should be sacrificed because they had already lived a long life, and the economic repercussions of COVID-19 restrictions on business and education of the young were too draconian in their effects on the non-elderly. Thankfully, for those who believe in the inherent value of every person's life and in the wisdom and experience of older people, this was not the course of action taken.

Those who suffer multiple forms of stigmatisation and feel devalued in society find it harder than higher status, socially valued individuals to change health behaviours, lacking resources and social encouragement to do so. The deprioritisation of older smokers is a symptom of institutionalised ageism, which must be addressed systematically to apply the tenets of health equity and inclusion in our work. Across all areas of tobacco control, we must do better by our elders.

Correction notice This paper has been updated since first published to update affiliation of author Tim McAfee.

Twitter Ruth E Malone @MaloneRuth

Funding The authors have not declared a specific grant for this research from any funding agency in the public, commercial or not-for-profit sectors.

Competing interests Tim McAfee has provided technical support as a consultant/sub-contractor working on a government-funded national media campaign and website encouraging people to quit smoking. Ruth Malone: See https://tobaccocontrol.bmj. com/pages/wp-content/uploads/sites/49/2019/10/DOIStatement-Ruth-Malone.pdf

Patient consent for publication Not required.

Provenance and peer review Not commissioned; not peer reviewed.

(C) Author(s) (or their employer(s)) 2021. No commercial re-use. See rights and permissions. Published by BMJ.

\section{A) Check for updates}

To cite McAfee T, Malone RE, Cataldo J. Tob Control 2021;30:479-480.

Published Online First 12 August 2021

Tob Control 2021;30:479-480.

doi:10.1136/tobaccocontrol-2021-056945

\section{ORCID iDs}

Tim McAfee http://orcid.org/0000-0001-80087-9817

Ruth E Malone http://orcid.org/0000-0002-3324-2183

\section{REFERENCES}

1 Pirie K, Peto R, Reeves GK, et al. The 21st century hazards of smoking and benefits of stopping: a prospective study of one million women in the UK. Lancet 2013;381:133-41.

2 Jha P, Ramasundarahettige C, Landsman V, et al. 21Stcentury hazards of smoking and benefits of cessation in the United States. N Engl J Med 2013;368:341-50.

3 McAfee T, Babb S, McNabb S, et al. Helping smokers quit--opportunities created by the Affordable Care Act. N Engl J Med 2015;372:5-7.

4 Jordan $\mathrm{H}$, Hidajat M, Payne N, et al. What are older smokers' attitudes to quitting and how are they managed in primary care? An analysis of the crosssectional English smoking toolkit study. BMJ Open 2017;7:e018150.

5 Schoeni RF, Martin LG, Andreski PM, et al. Persistent and growing socioeconomic disparities in disability among the elderly: 1982-2002. Am J Public Health 2005;95:2065-70.

6 Husten CG, Shelton DM, Chrismon JH, et al. Cigarette smoking and smoking cessation among older adults: United States, 1965-94. Tob Control 1997;6:175-80.

7 Isenberg JY, Quiñones AR, Slatore CG, et al. Trends in cigarette smoking and cessation among Medicare managed care recipients, 2005-2012. Addict Behav 2016;58:155-60.

8 Babb S, Malarcher A, Schauer G, et al. Quitting Smoking Among Adults - United States, 2000-2015. MMWR Morb Mortal Wkly Rep 2017;65:1457-64.
9 Thorndike AN, Rigotti NA, Stafford RS, et al. National patterns in the treatment of smokers by physicians. JAMA 1998;279:604-8.

10 Cataldo JK, Hunter M, Petersen AB, et al. Positive and instructive anti-smoking messages speak to older smokers: a focus group study. Tob Induc Dis 2015;13:2.

11 Centers for Disease Control and Prevention. CDC's National Network Approach to Preventing and Controlling Tobacco-related Cancers in Special Populations [website]. [updated 2/11/2021.] CDC's joint approach to tobacco-related cancer prevention in special populations through national networks sponsored by the Office on Smoking and Health and the Division of Cancer Prevention and Control], 2021. Available: https://www.cdc.gov/tobacco/ stateandcommunity/tobacco_control_programs/coopagreement/index.html

12 Centers for Disease Control and Prevention. Consortium of national networks to impact populations experiencing tobacco-related and cancer health disparities funding opportunity announcement. office on smoking and health, National center for chronic disease prevention and health promotion. Atlanta, GA: US Department of Health and Human Services, 2013.

13 Centers for Disease Control and Prevention (CDC). Cigarette smoking-attributable mortality and years of potential life lost--United States, 1990. MMWR Morb Mortal Wkly Rep 1993;42:645-9.

14 Ortman JM, Velkoff VA HH. An aging nation: the older population in the United States. Economics and Statistics Administration, ed. U. S. Census Bureau: U.S. Department of Commerce, 2014: 25-1140.

15 Cataldo JK, Malone RE. False promises: the tobacco industry, "low tar" cigarettes, and older smokers. J Am Geriatr Soc 2008;56:1716-23.

16 Dembart L. Tobacco Giant's Analysis Says Premature Deaths Cut Costs in Pensions and Healthcare: Critics Assail Phllip Morris Report on Smoking. New York Times, 2001

17 Arancini L, Borland R, Le Grande M, et al. Age as a predictor of quit attempts and quit success in smoking cessation: findings from the International tobacco control Four-Country survey (2002-14). Addiction 2021. doi:10.1111/add.15454. [Epub ahead of print: 02 Mar 2021].

18 Cataldo JK. Clinical implications of smoking and aging: breaking through the barriers. J Gerontol Nurs 2007;33:32-41.

19 Smith EA. 'It's interesting how few people die from smoking': tobacco industry efforts to minimize risk and discredit health promotion. Eur J Public Health 2007; 17:162-70.

20 Office of the Surgeon General. Smoking cessation: a report of the Surgeon General. Rockville, MD: U.S. Department of Health and Human Services, Public Health Service 2020.

21 Jia H, Lubetkin El. Dose-response effect of smoking status on quality-adjusted life years among U.S. adults aged 65 years and older. J Public Health 2017;39:e194-201.

22 Nash SH, Liao LM, Harris TB, et al. Cigarette smoking and mortality in adults aged 70 years and older: results from the NIH-AARP cohort. Am J Prev Med 2017:52:276-83.

23 Office of the Surgeon General. The health consequences of smoking: 50 years of progress: a report of the surgeon general. Rockville, MD: U.S. Department of Health and Human Services, Public Health Service 2014

24 Ahmad FB, Cisewski JA, Miniño A, et al. Provisional Mortality Data - United States, 2020. MMWR Morb Mortal Wkly Rep 2021;70:519-22. 